\title{
Analyzing Role of E-SERVQUAL Constructs for Post-pandemic Recovery of Indian Taxi Aggregator Services
}

\author{
Avadhut Arun Patwardhan ${ }^{1}\left[\right.$ [ $\cdot$ Neeraj Pandey ${ }^{2}$ (I)
}

Received: 15 May 2021 / Accepted: 13 October 2021 / Published online: 2 November 2021

(c) Global Institute of Flexible Systems Management 2021

\begin{abstract}
The taxi aggregator services leverage advantages of digital technologies that connect the provider and consumer. The mobile applications facilitate this online connectivity. The COVID-19 pandemic has impacted consumption of the taxi aggregator services in India due to the lockdown. However, the demand would be increasing as the relaxation would progress. Furthermore, the duopolistic Indian taxi aggregator market is highly competitive. The players would try hard to fulfill the demand for recovery and progress. This exercise would focus on brand loyalty intention for formulating customer retention strategies. Therefore, this study examined role of Efficiency, Privacy, and Contact (E-service Quality) constructs as antecedents to brand loyalty intention. A structured questionnaire was circulated online for collecting the data required for empirical validation of proposed model. Partial Least Square Structural Equation Modeling (PLS-SEM) was used for analyzing 288 responses. The results indicated that Efficiency, Privacy, and Contact influence the brand loyalty intention. Therefore, strategies emphasizing on efficiency, contact, and privacy would help both short-term and long-term customer retention. These strategies would act as a remedy for post-COVID recovery of taxi aggregator service providers.
\end{abstract}

Keywords E-service quality · Brand loyalty intention · Taxi aggregator service

\section{Introduction}

The taxi aggregator services leverage the benefits of information and communication technology (ICT)-based networks for shortening the length of supply chain. The digital technologies like mobile applications pass on these benefits by connecting the providers and consumers online.

Dash et al. (2021) reported that the taxi aggregator services are preferred over other modes of transportation by Indian consumers. This preference behavior of consumers has resulted into the growth of Indian taxi aggregator market. The Indian taxi aggregator market is growing at a compound annual growth rate (CAGR) of 19\% (Dash et al., 2021). According to Dash et al. (2021), the market would earn net sales of $\$ 52.5$ billion (INR 3806 billion) by 2024 , even though the COVID-19 pandemic has impacted the

Avadhut Arun Patwardhan

pharmaap@gmail.com

1 Vijay Patil School of Management (VPSM), Nerul, Navi Mumbai, India

2 National Institute of Industrial Engineering, Mumbai, India market growth negatively. This prediction indicates that the taxi aggregators would formulate strategies for post-pandemic recovery.

Kulkarni et al. (2019) mentioned that the Ola and Uber dominate the Indian taxi aggregator service market. This has made the Indian taxi aggregator market oligopolistic in nature. Furthermore, these players have ensured significant dominance by creating the entry barriers like deep discounting and predatory pricing. In case of post-pandemic progress, these aforementioned approaches will not work. This demands a workable solution that could facilitate the progress in both short and long run.

Huang and Jahromi (2021) reported that market orientation strategy would help taxi aggregators in dealing with the post-pandemic challenges. This strategy proposes to examine the consumer behavior for developing marketing intelligence. Kulkarni et al. (2019) reported that the consumer preferences are rapidly evolving in the context of taxi aggregator services. Furthermore, the non-price factors like increased technological efficiencies influence the consumer preferences.

Nguyen-Phuoc et al. (2021) reported that consumer loyalty plays an important role in the consumption of taxi 
aggregator services. In case of oligopolistic taxi aggregator, market like India role of brand loyalty intention becomes crucial for formulating the strategies. Therefore, determining the factors that influence brand loyalty of taxi aggregator service users becomes a key.

Nguyen-Phuoc et al. (2021) mentioned that the taxi aggregator service may be viewed as phases. These phases are pre-booking and post-consumption. In case of present study, the taxi aggregator service is viewed as a three-stage experience. These stages are pre-consumption, consumption and post-consumption stage.

The per-consumption stage deals with seeking and searching availability of the vehicle and booking a vehicle. As per the past researchers, in case of websites and mobilebased applications, the construct Efficiency emphasizes on appearance, search options, and interactive function of the technology (Santos, 2003). Furthermore, these alternatives enrich customer experience by providing information about the product/service availability status (Trocchia \& Janda, 2003). This scenario highlighted role and relevance of construct efficiency.

The consumption stage is a second stage. At this stage, the consumer consumes the service. The passenger commutes from one location to another location. Past researchers (Barrutia \& Gilsanz, 2009) reported that technological initiatives (like telephone, online forums, and chats) helped service providers in communicating with and assisting to the consumer. In another word, the technological developments helped service providers in establishing contact with the customers. Both online and offline communications are viewed as quality dimensions (Loonam \& O'Loughlin, 2008). In case of taxi aggregator service users, the customer may access the mobile application to verify the route during the consumption stage. The consumers of taxi aggregator services may experience constant contact from the service provider by receiving information about live location of the driver, approximate travel time, facility to share travel details with family, and live updates about traffic conditions. These aforementioned aspects underlined the importance of contact in the context of present study.

The post-consumption stage deals with completion of transactions. There are two options that are considered by the consumers. The consumer may choose to pay cash payment or may go for online payment option. According to Suh et al. (2013), privacy is customer's belief related to online transactions. These beliefs are related to risk associated with online transactions. Therefore, exploring relevance of privacy for taxi aggregator service users is necessary.

Consumers of taxi aggregator services use mobile applications for completing aforementioned consumption stages. These aspects indicated the importance of understanding role of e-service quality constructs (Efficiency, Contact, and Privacy) in the context of taxi aggregator service users. Past and contemporary researchers have examined the role of E-Service quality constructs as antecedents to perceived value. These examinations have proposed implications related to value enhancement. However, relevance of these constructs for enhancing loyalty intention is not studied. This has created a scope for the present study.

Therefore, this study emphasizes on examining the research questions:

RQ1-Whether the construct efficiency impacts the perceived value and brand loyalty intention?

RQ2-Whether the construct contact influences the perceived value and brand loyalty intention?

RQ3-Whether the construct privacy influences the perceived value and brand loyalty intention?

This paper is divided into various sections and sub-sections for having a systematic structure. The next section justified importance of considering Perceived value and Brand Loyalty in the context of taxi aggregator service. The third section mentioned about the hypotheses developed on the basis of the theoretical back ground and conceptual models. The fourth section provided the methodological details of the study. The fifth section reported about the data analysis techniques considered and presented the results of the analysis. The sixth section discussed outcomes of the study in light of past research outcomes. The seventh section underlined the conclusions and implications of the study. The eighth section mentioned reported about the limitations and future scope of the study. The last sections reported the key questions reflecting the real-life relevance of the present study.

\section{The Linkage Between Perceived Value, Brand Loyalty, and Consumption of Taxi Aggregator Service}

The pioneer researcher (Zeithmal, 1988) reported that consumer's perception toward product/service determines the perceived value. The next sub-section discussed the role of perceived value.

\section{Role of Perceived Value}

Parasuraman and Grewal (2000) proposed a model emphasizing on the transactional exchange. This model consists of two components as "get" component and "give" component. In case of perceived value, the service quality is the "get" component and price paid is the "give" component (Grewal et al., 1998; Zeithmal, 1988). This logic emphasized 
on the net trade-off between relevant benefits received from the products or services and the costs/sacrifices made while consumption (Gera, 2011; Parasuraman et al., 2000). Chang et al. (2009) mentioned that the past literature viewed perceived value as the value offered before buying, at the time of buying and during and after use of product and services. Furthermore, Katono (2011) reported that perceived value is an outcome of pre-purchase expectations and post-usage perceptions. These views indicate that perceived value deals with pre- and post-consumption experiences.

Kurt and Atrek (2012) reported that attractive quality attributes offer higher value and lead to competitive advantage. On the basis of a survey conducted for the Indian consumers, Kandulapati and Bellamkonda (2014) mentioned that e-SQ dimensions affects perceived service value that affect perceived value. Kim and Niehm (2009) and Pearson et al. (2012) reported that choice preference behavior is a result of interactions with and relative experiences of the consumers. The dimensions like payments made and consumer sacrifices experienced (Chang et al., 2009) make perceived value relativistic.

Furthermore, the past and contemporary researchers (Atinuke et al., 2016; Blut, 2016; Einasto, 2014; Kalia, 2017; Kundu \& Datta, 2015; Lee \& Lin, 2005; Loonam \& O'Loughlin, 2008; Pearson et al., 2012; Stamenkov \& Dika, 2015; Suh et al., 2013) mentioned that readable, logical, functional, visually appealing and useful online alternatives provide customers easier user interface experience. Hence, to stay relevant and competitive as a service provider exploring the components of perceived value becomes essential.

In case of the taxi-aggregator service users, the perceived value would be a result of the three-stage experience explained as a part of introduction. Therefore, the perceived value may be achieved by offering relevant benefits, easier and risk-free transactions and enhance utility (Parasuraman \& Grewal, 2000) at the various stages of consumption.

The loyalty behavior is the second important aspect that was examined by the past service quality researchers. Brand loyalty is viewed as indicator of commitment of consumers. This construct is measured by intention to repurchase (Oliver, 1999). Loyalty is also explained with the help of a four-stage process. These stages are cognitive stage, affective stage, conative stage, and action stage, respectively. Out of these stages, the second stage deals with the service experiences and satisfaction. The following sub-section discussed the role of brand loyalty in the context of service experience.

\section{Role of Brand Loyalty}

The past researchers viewed loyalty as an increased tendency/intention to repurchase (Anderson \& Srinivasan, 2003) and favorable attitude (Sahadev \& Purani, 2008). According to Anderson and Srinivasan (2003) increased purchasing intentions, recommendation behavior and tendency to pay additional price are the indicators of loyalty. The past marketing researchers (Cristobal et al., 2007; Dabholkar \& Overby, 2005) reported that that repurchase of a product or service is a result of quality perceptions. Loonam and O'Loughlin (2008) and Yen and Lu (2008) opined that attitudinal change impact customer retention, hence the service quality perceptions help in retaining customer and creating a reputable brand (Zeithmal et al. 1996). Atinuke et al. (2016), Chang et al. (2009), and Stamenkov and Dika (2015) reconfirmed the significant relationship between the quality perceptions with loyalty. These aforementioned aspects underline that service quality dimensions are significantly important for determining the loyalty behavior of consumers.

Considering these aspects, this study decided to examine the role of e-service quality constructs (Efficiency, Contact, and Privacy) as antecedents of Perceived Value and Brand Loyalty Intention. The details in this regard are discussed in the next section.

\section{Hypotheses Development and Conceptual Models}

\section{Contact and Effect of Contact}

Past studies (Parasuraman, 2006; Yen \& Lu, 2008) mentioned that service providers contact and communicate with the customers. The alternatives like telephone or online representatives, online forums, and chats assisted service providers in communicating with customers (Barrutia \& Gilsanz, 2009). These alternatives provided detailed information about service to customers. In case of consumption of services, the customer support is expected by the customers and viewed as dimension of service quality (Bhattacharya et al., 2012; Sahadev \& Purani, 2008; Stiakakis \& Georgiadis, 2009). The increased availability of technology-based options like websites, mobile applications, and social media (Suh et al., 2013) has increased the ability of service providers in providing customer support. This information may be consisted of e-mail addresses; contact details of officials and other support staff members. Both online and offline contact/communication (s) are viewed as quality dimensions (Loonam \& O'Loughlin, 2008).

Chang et al. (2009) suggested that organizations may maintain effective contact with the consumers using multiple channels, whereas inefficiency in this regard may enhance dissatisfaction among consumers (Herington \& Weaven, 
2009; Jabnoun \& Al-Tamimi, 2003). Furthermore, Sahadev and Purani (2008) mentioned that relevant, timely, and meaningful communication may lead to increased loyalty. According to Gera (2011), interaction experience created using effective channel contacts affects consumer decisionmaking and leads to enhanced loyalty and recommendations.

On the basis of this literature support, the following hypotheses were formulated.

H1-The e-service quality construct contact positively affects the perceived value.

H2-The e-service quality construct contact positively affects the brand loyalty intention.

\section{Privacy and Effect of Privacy}

Cristobal et al. (2007) reported that privacy is a key construct of service quality scale that affects the image of the service provider. Privacy is the aspect associated with authentication and confidentiality (Cristobal et al., 2007). Further researchers (Blut, 2016; Einasto, 2014; Kurt \& Atrek, 2012; Lee \& Lin, 2005; Santos, 2003) opined that privacy is a concern related to risk of fraud (Barrutia \& Gilsanz, 2009). Rolland and Freeman (2010) mentioned that even though the "security/privacy" constructs are used interchangeably, there is a subtle difference. According to Rolland and Freeman (2010), the security deals with "clear information on security" and "adequacy of security features" and privacy deals with "appropriate use of personal information". Bhattacharya et al. (2012) opined that security dimensions are concerns related with hacking, phishing, and spamming, whereas privacy dimensions are concerns related with identity theft.

Privacy was also found as a factor affecting perceived value (Heim \& Field, 2007). Herington and Weaven (2009) and Jayawardhena (2004) reported that in the context of services (like banks), security and privacy are very important factors associated with trust (Kundu \& Datta, 2015). As an extension to the aforementioned outcome, Sabiote et al. (2012) underlined that incase of cultures that avoid high uncertainty, privacy is one of the important aspects related to consumption of services. India also follows the high uncertainty avoidance culture. Therefore, considering privacy has become essential in case of studies conducted in India. According to Bhattacharya et al. (2012), privacy influences the attitudinal aspect related to e-service quality and perceived risks. Kundu and Datta (2015) reported that security is an important aspect for developing trust among customers consuming Internet retail services. Atinuke et al. (2016) mentioned that security influences acceptance and satisfaction.
These knowledge contributions underline positive relationship of privacy with service quality. These contributions also indicate relevance of privacy in the context of geographical culture.

Therefore, on the basis of these aspects, this study formulated following hypotheses:

H3-The construct privacy positively affects the perceived value.

H4-The construct privacy positively affects the brand loyalty intention.

\section{Efficiency and Effect of Efficiency}

Santos (2003) reported that construct efficiency emphasizes on appearance, search options, and interactive function of the online interaction alternative like websites and mobile applications (Keeney 1999). According to Trocchia and Janda (2003), these alternatives enrich customer experience by providing information related to availability, characteristics/qualities of product/services, and price comparisons. Parasuraman et al. (2000) in the seminal contribution viewed efficiency as key influencing factor of e-service quality. This factor affects customer satisfaction. Furthermore, Lee and Lin (2005) mentioned that efficiency affects the evaluation of services. This may affect perceived image (Sohn \& Tadisina, 2008) and repurchase intentions (Cristobal et al., 2007). Herington and Weaven (2009) opined that efficiency acts as hygiene factor in case of technology-based services like e-banking and may influence the level of satisfaction. Carlson and O'Cass (2011) reported that efficiency determines consumer's attitude which leads to the enhanced revisit intentions and recommendation behavior. Stiakakis and Georgiadis (2009) reported that efficiency also influences e-service's adoption.

Aladwani and Palvia (2002) have underlined two important aspects of online alternatives which are navigation and aesthetics. Anderson and Srinivasan (2003) suggested that the efficiency dimensions lead to e-customer satisfaction. Loonam and O'Loughlin (2008) mentioned that usability of an online alternative contributes to a firm's online success (Cox \& Dale, 2001). Stiakakis and Georgiadis (2009) highlighted that aspects like uploading and downloading of information, efficiency of search options and responses, page organization (Trocchia \& Janda, 2003), comprehensiveness, content completeness (Sohn \& Tadisina, 2008), sufficiency, and detailed contact (Ladhari, 2010) are the components of efficiency/user interface experience.

According to Barrutia and Gilsanz (2009), ease in finding the web site, availability of information, downloading speed, quantity, quality and credibility of information, 
speed of transactions, and ease of navigation (Kim \& Kim, 2010) are some more components of efficiency. According to Ladhari (2010), effective design of online alternatives influences customer perceptions (Shih 2004) and behavioral intentions. Sabiote et al. (2012) revealed that ease of use (Muylle et al. 2004) shares significant and positive relationship with satisfaction. Kandulapati and Bellamkonda (2014) reported that efficiency positively and significantly affects overall e-SQ, service value, and customer satisfaction, respectively.

These aspects indicate that incase of service quality, research efficiency is a highly considered and wellresearched construct. Therefore, relevance of this construct could be examined.

H5-The construct efficiency positively affects the perceived value.

H6-The construct efficiency positively affects the brand loyalty intention.

The past studies revealed that these constructs act as an antecedent of perceived value. Furthermore, these studies also treated perceived value as a mediator between E-Service quality constructs and Brand loyalty intention. A very few studies have checked direct impact of e-service quality constructs on brand loyalty intention dimensions identified in the study are based on a full assessment of an e-service experience. The present study considered this as a gap and did the empirical validation treating efficiency, privacy, and contact as antecedents and brand loyalty intention.

On the basis of these aspects, two models are conceptualized. The conceptual models depicting the hypothesized relationships are presented in Figs. 1 and 2. The various constructs considered in the model are denoted by abbreviations. The construct contact is presented as CNT, Efficiency as EFF, Privacy as PRV, Perceived Value as PV, and Brand Loyalty Intention as BLI.

\section{Methodology}

To achieve the predefined research questions, a systematic methodological approach was adopted. During the literature review, 56 papers were reviewed to formulate appropriate methodology. Furthermore, the prominent research trends identified during the literature review were used for adding the methodological rigor.

The results of trend analysis revealed that the quantitative research approaches were prominently used (33 studies out of 50) by past researchers. This means that deploying quantitative research methods has become a contemporary trend in case of service quality research. The results also indicated that majority of the studies

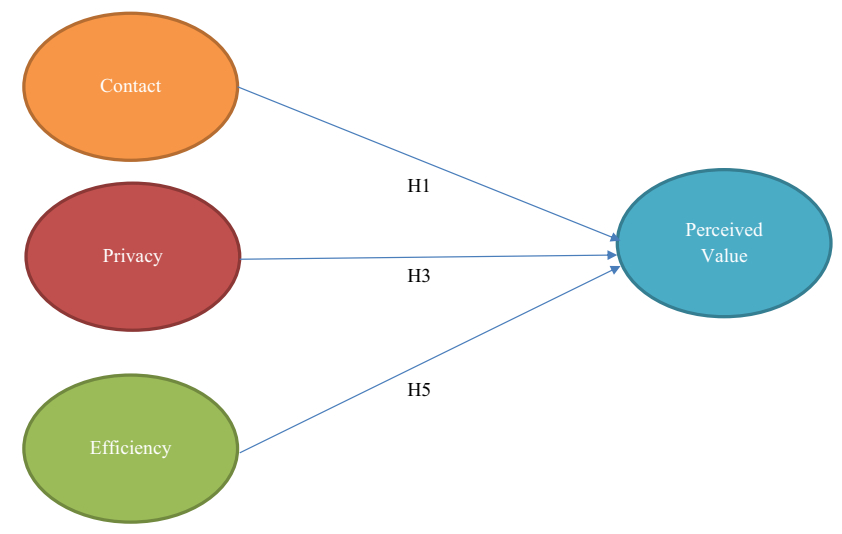

Fig. 1 Conceptual model prepared by considering Perceived Value as dependent variable

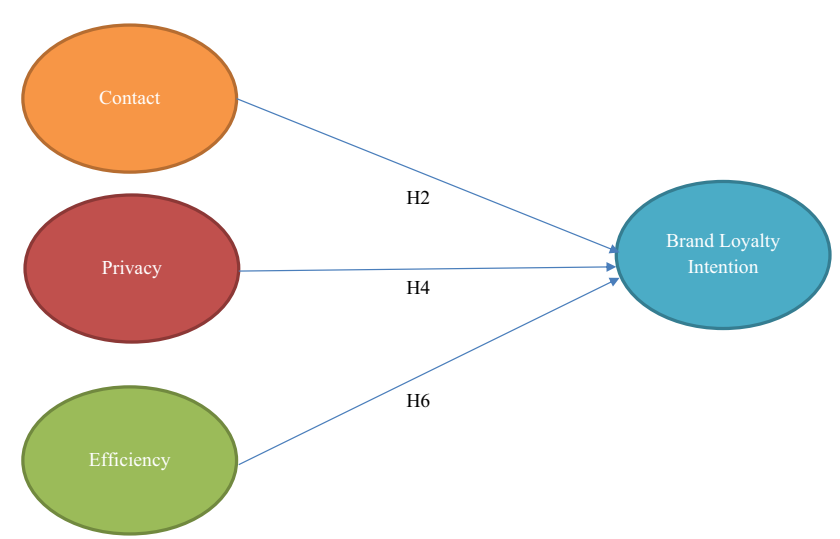

Fig. 2 Conceptual model prepared by considering Brand Loyalty Intention as dependent variable

belong to survey-based studies. Questionnaire was used as referred method of data collection.

The contemporary management researchers have been experiencing some of the challenges like limited number of respondents leading to smaller sample sizes, lack of interest while participating in a survey leading to biased responses. In such challenging scenarios when data are inadequate and heterogeneous, use of PLS-SEM was found considerable. Furthermore, the traditional co-variance-based SEM (Structural Equation Modeling) demands fulfillment of the multivariate assumption and normality of data is one among these assumptions. Therefore, to deal with the data appropriately, this study decided to use PLS-SEM as a method for analyzing the data. The methodological details are presented as the various sub-sections. 


\section{Sampling}

This study considered Internet and Mobile Association of India (IAMAI, 2017) report for determining respondents. The report informed that majority of the smart phone users belong to urban area. Furthermore, majority of the respondents belong to age group 25-60 years. The report also indicated that the usage of smart phone is dominated by male users. Therefore, the target population considered for this study was smart phone users from the urban area and belongs to age group 25-60. Furthermore, the smartphone users who use mobile applications for consuming tax aggregator services were considered for collecting data. This target population justified both scope and context of the study. The convenience sampling technique (Carlson \& O'cass, 2011; Jain et al., 2017) was used for collecting the data. Even though the convenience sampling technique was deployed, to collect the data from appropriate respondents, certain qualifiers were used while designing the questionnaire.

\section{Questionnaire Designing and Measurement of Constructs}

This study developed a self-administered survey. The data were collected by administering the survey online. A systematic process predominantly used in consumer behavior research and proposed by Carlson and O'Cass (2011) was used for designing the questionnaire. This process consists of item generation using literature, item-validation (through expert survey and/or focus group), and pilot administration. Similar approach was used by Jain et al. (2017). This study used the seminal paper by Parasuraman et al. (2000) for operationalizing the constructs considered in the study. These items are adopted (Parasuraman et al., 2000) and modified to enhance appropriateness with the context.

This study used pre-testing of the instrument designed for ensuring face and content validity of the items generated through literature review. As a part of pre-testing, a focused group discussion consisting of the 10 participants was conducted. The pre-testing consisted of involvement of 3 experts from the industry, 2 academicians, 3 respondents, and 2 post-graduate management program (M.B.A.) students. The participants were asked to identify the items that measure the constructs considered for the study. The discussion resulted into identification of 3 items for privacy and contact constructs. Furthermore, the participants unanimously suggested to reduce the number of items from 10 to 3 for the construct efficiency. The participants confirmed that the items identified for perceived value and brand loyalty intention are appropriate. The instrument was further piloted among 28 post-graduate students who have consumed the services from Taxi aggregators to check reliability of questionnaire.

The questionnaire used for final data collection consists of two parts: the first part collects demographic data of respondents and the second part includes items used for measuring constructs. The questionnaire consisted of total 18 items measuring 5 constructs. The constructs privacy, contact, and efficiency were operationalized with 3 items each. The constructs perceived value and brand loyalty intention were operationalized using 4 and 5 items, respectively. The items were measured on 5-point Likert scale (Jain et al., 2017). The questionnaire used for data collection is attached as an appendix for ready reference of the readers.

\section{Method of Data Analysis}

The outcomes of literature review revealed that quantitative data collected by past service quality researchers were analyzed with the help of various techniques. The techniques were Regression Analysis, Exploratory Factor Analysis (EFA), Confirmatory Factor Analysis (CFA), Structural Equation Modeling (SEM), and Partial Least Squares (PLS-SEM).

PLS-SEM has gained prevailing importance in almost all the domains of management (Kaufmann \& Gaeckler, 2015). According to Hair et al. (2014), domains like marketing management, strategic management, management information systems, production and operations managements, and accounting have been using PLS-SEM. According to Hair et al. (2019), services' management could be an upcoming avenue for the PLS-SEM research. Furthermore, past researchers (Carlson and O'Cass, 2011) reported that in case of service quality research, the partial least-squares (PLS) path modeling was found useful. The similar approach was used by past researchers (Atinuke et al., 2016; Gera, 2011; Kim \& Kim, 2010; Kundu \& Datta, 2015; Kurt \& Atrek, 2012; Sabiote et al., 2012; Sohn \& Tadisina, 2008; Stamenkov \& Dika, 2015; Yen \& Lu, 2008).

According to Sarstedt et al. (2012), Hair et al. (2014) and Nitzl (2016) PLS-SEM is useful for both small and big data sets. In case of non-normal data, this method is predominantly preferred. This method deals with assessment of measurement model (useful for scale development) and prediction of structural model (useful for hypothesis testing). As this study was emphasizing on theory testing and not on scale development, the Confirmatory Factor Analysis (CFA) was not done. 
Considering the methodological and contextual relevance, this study used PLS-SEM. The sample size of 288 responses was consistent with earlier studies conducted in the area of e-service quality (Carlson and O'Cass, 2011). The 288 data points were also found appropriate for deploying PLS-SEM (Hair et al., 2019; Jain et al., 2017). The details of data analysis and results are discussed in next section.

\section{Data Analysis and Results}

The data collection resulted into collection of total 323 responses. 23 responses were found incomplete and 12 responses unusable. Therefore, these responses were not considered in the data analysis. 288 effective responses were retained for data analysis. The gender-wise classification of respondent indicates that the sample is consisted of 197 urban males (68\%) and 91 urban females (32\%). These data were found relevant with IAMAI (2017) report that indicates similar demographics.

This study used PLSPM package of R software for analysis. Carlson and O'Cass (2011) reported that the results of PLS-SEM include two measure components. These components are evaluation of the structural model and measurement model. Out of these two components, measurement model deals with examination of appropriateness of measures and the structural model assesses the relationship hypothesized between the constructs.

\section{Unidimensionality}

According to Carlson and O'cass (2011), various indicators are considered for evaluating the results of PLS Path Model. In case of reflective measures, unidimensionality is checked. This study has used reflective measures for measuring the desired constructs considered in two conceptual models. Therefore, the unidimensionality was checked with the help of various parameters. These parameters were Cronbach's Alpha, Dillon-Goldsein's rho, Eigen value1, and Eigen value2.

Carlson and O'cass (2011) reported that in case of PLS-SEM path modeling, composite reliability is used to check the internal consistency and the convergent validity is determined measuring the AVE. The results presented in Tables 2 and 3 confirm that in case of both model 1 and model 2, the construct considered fulfills the criteria proposed by the aforementioned researchers. The results of the unidimensionality of the indicators are presented in Table 1.

\section{Convergent Validity}

According to Carlson and O'Cass (2011), Hair et al. (2014), and Jain et al. (2020), factor loadings and the average variance extracted (AVE) are the indicators examined for confirming the convergent validity.

The results indicated that in case of both outer-measurement models and the first-order factors, the loadings are higher than 0.70 . Furthermore, the communalities were also found fulfilling the range criteria $(0.6-0.9)$. The researchers (Carlson \& O'Cass, 2011; Hair et al., 2014; Jain et al., 2020) mentioned that the AVE value should be higher than 0.5 to fulfill the convergent validity. In case of present study, the value of AVE by the respective constructs is higher than 0.5 .

These results confirm that constructs considered in conceptual model 1 and 2 achieve the convergent validity satisfactorily. The results are presented in Tables 2 and 3.

\section{Discriminant Validity}

Prominent researchers (Atinuke et al., 2016; Carlson \& O'Cass, 2011; Pearson et al., 2012) reported that the discriminant validity is confirmed by comparing the square root of the AVE with the correlations of corresponding constructs.

Table 1 Unidimensionality of the constructs

\begin{tabular}{llllll}
\hline Indicators of unidimensionality & Cronbach's alpha & Dillon-Goldstein rho & Eigen value indicator 1 & Eigen value indicator 2 \\
\hline EFFI (3) & Model 1 & 0.76 & 0.86 & 2.0 & 0.53 \\
& Model 2 & 0.75 & 0.86 & 2.0 & 0.53 \\
PRV (3) & Model 1 & 0.81 & 0.88 & 2.1 & 0.53 \\
& Model 2 & 0.80 & 0.88 & 2.1 & 0.53 \\
CNTC (3) & Model 1 & 0.87 & 0.92 & 2.3 & 0.39 \\
& Model 2 & 0.87 & 0.92 & 2.3 & 0.39 \\
PV (4) & Model 1 & 0.84 & 0.89 & 2.6 & 0.52 \\
BLI (5) & Model 2 & 0.91 & 0.93 & 3.7 & 0.52 \\
Threshold & & Value $>0.7$ & Value $>0.7$ & Value $>1.0$ & Value $<1.0$ \\
Comment & & Acceptable & Acceptable & Acceptable & Acceptable \\
\hline
\end{tabular}


Table 2 Convergent validity Model 1

\begin{tabular}{|c|c|c|c|c|c|c|}
\hline Construct & Block parameters & Loadings & Communalities & AVE & Thresholds & Remarks \\
\hline \multirow[t]{3}{*}{ EFFI (3) Model 1} & EFFI5 & 0.789 & 0.623 & \multirow[t]{3}{*}{0.671} & For loading & \multirow[t]{3}{*}{ Acceptable } \\
\hline & EFFI6 & 0.866 & 0.750 & & Value $>0.7$ & \\
\hline & EFFI7 & 0.800 & 0.640 & & & \\
\hline \multirow[t]{3}{*}{ PRV (3) Model 1} & PRV1 & 0.815 & 0.664 & \multirow[t]{3}{*}{0.718} & For communalities & \multirow[t]{3}{*}{ Acceptable } \\
\hline & PRV2 & 0.877 & 0.769 & & Value of loadings $>0.7$ & \\
\hline & PRV3 & 0.850 & 0.723 & & & \\
\hline \multirow[t]{3}{*}{ CNTC (3) Model 1} & CNTC1 & 0.863 & 0.745 & \multirow[t]{3}{*}{0.794} & Cross loadings & \multirow[t]{3}{*}{ Acceptable } \\
\hline & CNTC2 & 0.928 & 0.861 & & Values of the block param- & \\
\hline & CNTC3 & 0.880 & 0.774 & & $\begin{array}{l}\text { eters }>\text { Other parameters in the } \\
\text { row }\end{array}$ & \\
\hline \multirow[t]{4}{*}{ PV (4) Model 1} & PV1 & 0.753 & 0.567 & \multirow[t]{4}{*}{0.670} & For AVE & \multirow[t]{4}{*}{ Acceptable } \\
\hline & PV2 & 0.819 & 0.671 & & Value $>0.5$ & \\
\hline & PV3 & 0.848 & 0.719 & & & \\
\hline & PV4 & 0.851 & 0.724 & & & \\
\hline
\end{tabular}

Table 3 Convergent validity Model 2

\begin{tabular}{|c|c|c|c|c|c|c|}
\hline Construct & Block parameters & Loadings & Communalities & AVE & Thresholds & Remarks \\
\hline \multirow[t]{3}{*}{ EFFI (3) Model 2} & EFFI5 & 0.800 & 0.640 & \multirow[t]{3}{*}{0.672} & For loading & \multirow[t]{3}{*}{ Acceptable } \\
\hline & EFFI6 & 0.858 & 0.737 & & Value $>0.7$ & \\
\hline & EFFI7 & 0.799 & 0.639 & & & \\
\hline \multirow[t]{3}{*}{ PRV (3) Model 2} & PRV1 & 0.826 & 0.683 & \multirow[t]{3}{*}{0.721} & For communalities & \multirow[t]{3}{*}{ Acceptable } \\
\hline & PRV2 & 0.891 & 0.794 & & Value of loadings $>0.7$ & \\
\hline & PRV3 & 0.850 & 0.687 & & & \\
\hline \multirow[t]{3}{*}{ CNTC (3) Model 2} & CNTC1 & 0.866 & 0.751 & \multirow[t]{3}{*}{0.794} & Cross loadings & \multirow[t]{3}{*}{ Acceptable } \\
\hline & CNTC2 & 0.924 & 0.854 & & Values of the block param- & \\
\hline & CNTC3 & 0.891 & 0.777 & & $\begin{array}{l}\text { eters }>\text { Other parameters in the } \\
\text { row }\end{array}$ & \\
\hline \multirow[t]{5}{*}{ BLI (5) Model 2} & BLI1 & 0.837 & 0.700 & \multirow[t]{5}{*}{0.746} & For AVE & \multirow[t]{5}{*}{ Acceptable } \\
\hline & BLI 2 & 0.908 & 0.824 & & Value $>0.5$ & \\
\hline & BLI 3 & 0.908 & 0.825 & & & \\
\hline & BLI 4 & 0.838 & 0.702 & & & \\
\hline & BLI5 & 0.822 & 0.676 & & & \\
\hline
\end{tabular}

According to O'Cass and $\mathrm{Ngo}$ (2007), if the loadings of block parameters of a construct are higher than the off-diagonal entries of other constructs, the discriminant validity is achieved. Carlson and O'cass (2011) suggested to confirm discriminant validity researcher need to assess the cross loadings matrix. In case of this paper, both the approaches were deployed. The results of first approach are presented separately as Tables 4 and 5.

\section{Hypothesis Testing}

Carlson and O'Cass (2011) reported that the predictive power of the dependent construct was also examined with the help of $R^{2}$. In case of perceived value, the $R^{2}$ value is $(0.32)$ and for brand loyalty intention (0.33). These values are accepted as moderate values as per the aforementioned reference. Furthermore, Carlson and O'Cass (2011) also suggested to consider redundancy and goodness of fit as indicators of predictor power. In case of perceived value, redundancy was 0.21 , whereas goodness of fit was 0.48 . The redundancy was 0.24 and goodness of fit was 0.49 in case of brand loyalty intention. These indicators fall in the range of acceptance and considered as moderate predictors. The AVE by perceived value was 0.67 which for brand loyalty intention is 0.74 .

Carlson and O'Cass (2011) mentioned that the $t$ value is considered when PLS-SEM is used for hypothesis testing. Table 6 shows the results of nonparametric bootstrapping routine performed with 288 cases and 5000 samples (Jain et al. 2020). Path coefficients achieved as a result of this analysis act as parameters for assessing the structural model. This assessment indicate that the constructs contact, privacy, 
and efficiency act as an antecedent of both perceived value $(\mathrm{H} 1, \mathrm{H} 3, \mathrm{H} 5)$ and brand loyalty intention $(\mathrm{H} 2, \mathrm{H} 4, \mathrm{H} 6)$. Therefore, all the hypotheses were accepted. The details of the analysis are presented in Table 6.

\section{Discussion}

The introduction of technology has enhanced the efficiency and increased contact with the customers. Furthermore, the online transactions have increased concerns of consumers toward privacy. These aspects may positively impact the perceived value and loyalty intentions of the taxi aggregator service users. To examine the impact, two models were developed considering perceived value and brand loyalty intention as dependent variables. These models treated efficiency, privacy, and contact as antecedents of perceived value and brand loyalty intention. The outcomes of these examinations are discussed in line with the past studies.

Impact of efficiency-Sahadev and Purani (2008) discussed that efficiency was found a significant factor affecting various dependent variables irrespective of type of e-service. Gera (2011) showed that the positive evaluations and behavioral responses of general web users are dependent on website experience/efficiency. Present study confirmed that the efficiency of the mobile applications impacts the perceived value of the service offered. This indicates that the findings are consistent with the past evidences. Similar results are achieved in the context of this study that considered mobile application users of taxi aggregator services. The findings are also consistent with the study conducted by Kim and Kim (2010) for respondents from Korea and USA. This also indicate that the past explorations are relevant for the different geographical and technological contexts. Furthermore, in case of this study, efficiency is also found as an antecedent of brand loyalty intention.

Impact of privacy-Rolland and Freeman (2010) reported that privacy is a major concern associated with service quality perceptions. This effect intern leads to impact on perceived value. A study that focused on online shoppers from Turkey revealed that Privacy is the most important component in case of Turkish customers (Kurt \& Atrek, 2012). A study conducted by Sheng and Liu (2010) reported that privacy is not a predictor of loyalty in case of online customer's loyalty behavior. The outcome
Table 4 Discriminant validity Model 1

\begin{tabular}{lllllll}
\hline Construct & EFFI & PRV & CNTC & PV & & \\
\hline EFFI & $\mathbf{0 . 8 1 9}$ & & & & For discriminant validity & Acceptable \\
PRV & 0.269 & $\mathbf{0 . 8 4 7}$ & & & Square root of AVE $>$ Correlations & \\
CNTC & 0.192 & 0.340 & $\mathbf{0 . 8 9 1}$ & & & \\
PV & 0.418 & 0.456 & 0.327 & $\mathbf{0 . 8 1 8}$ & & \\
\hline
\end{tabular}

Bold indicate that the discriminant validity is achieved
Table 5 Discriminant validity Model 2

\begin{tabular}{lllllll}
\hline Construct & EFFI & PRV & CNTC & BLI & & \\
\hline EFFI & $\mathbf{0 . 8 1 9}$ & & & & For discriminant validity & Acceptable \\
PRV & 0.266 & $\mathbf{0 . 8 4 9}$ & & & Square root of AVE $>$ Correlations & \\
CNTC & 0.192 & 0.342 & $\mathbf{0 . 8 9 1}$ & & & \\
BLI & 0.395 & 0.485 & 0.322 & $\mathbf{0 . 8 6 3}$ & & \\
\hline
\end{tabular}

Bold indicate that the discriminant validity is achieved

Table 6 Result of hypothesis testing

\begin{tabular}{|c|c|c|c|}
\hline Hypothesis & $t$ value & Threshold & Remark \\
\hline $\begin{array}{l}\text { H1-The organization's ability to connect with customers positively affects the per- } \\
\text { ceived value }\end{array}$ & 5.91 & $t$ value $>1.65$ & Accepted \\
\hline $\begin{array}{l}\text { H2-The organization's ability to connect with customers positively affects the brand } \\
\text { loyalty intention }\end{array}$ & 2.81 & $t$ value $>1.65$ & Accepted \\
\hline H3-The construct privacy positively affects the perceived value & 6.03 & $t$ value $>1.65$ & Accepted \\
\hline H4-The construct privacy positively affects the brand loyalty intention & 5.34 & $t$ value $>1.65$ & Accepted \\
\hline H5-The construct efficiency positively affects the perceived value & 3.07 & $t$ value $>1.65$ & Accepted \\
\hline H6-The construct efficiency positively affects the brand loyalty intention & 6.86 & $t$ value $>1.65$ & Accepted \\
\hline
\end{tabular}


of present study indicated that the concerns related to privacy impact the loyalty of the Indian consumers. In case of India, the taxi aggregator service users who are opting for an online payment method may become concerned about privacy related to personal information. This paper revealed that in the context of Taxi aggregators, mobile application user's privacy is significantly associated with perceived value and loyalty. This study revealed that the relevance of privacy changes according to the geographical context. This outcome also indicates that privacy which is not a concern in the context of online shopping is a concern for the taxi aggregator service users. This intern indicates that the contextual differences are need to consider for validation of previously proposed relationships. This exercise would further enhance the generalizability of the existing theory.

Impact of contact-Yen and $\mathrm{Lu}$ (2008) conducted a study emphasizing on online auction. The outcomes of the study revealed that in case of online auction, the construct 'contact' played an important role. Elsharnouby and Maharous (2015) conducted a study focusing on participation in online co-creation. The study analyzed role of e-service quality constructs and reported that contact plays an important role in this context. The present study found that the construct contact impacted both perceived value and brand loyalty intention of taxi aggregator service users. This outcome indicated that role of contact is generalizable across various geographical and technological contexts. Dhir \& Dhir (2018) mentioned that business competitiveness act as a factor for business success in the context of e-commerce. In case of taxi aggregator services the competitiveness (Momaya, 2019) may be viewed as technological efficiency, consistent contact and privacy during electronic transactions.

\section{Conclusion and Implications}

This study concluded that the e-service quality constructs (contact, privacy, and efficiency) act as an antecedent to both the dependent variables perceived value and brand loyalty intention. Huang and Jahromi (2021) reported that in case of post-pandemic recovery of taxi aggregator services responding to the market requirements is essential. This can be achieved with the help of market orientation approach. Maintaining contact with and enhancing network of customers, developing technologies for responding to the current and future needs of taxi aggregator users will be the steps that could help the service providers (Huang \& Jahromi, 2021). These deliberations indicate that the maintaining and retaining contact with the customers and improving technological efficiency is essential. These are the factors that would facilitate the post-pandemic progress of taxi aggregator service providers operating in India.

As a theoretical contribution, this study contributes to the literature emphasizing on e-service quality, perceived value, and brand loyalty. This study explores the relevance of e-service quality constructs for the novel context of taxi aggregator service users and confirms the generalizability of the seminal works (Parasuraman, 2006; Parasuraman et al., 2000). Surprisingly, this study found the e-service quality constructs as an antecedents of brand loyalty intentions. This exploration may help the researcher to gain deeper insights in the contexts taxi aggregator service users. Chiou \& Shen (2006) contributed to the e-commerce service studies by examining how antecedents of consumer loyalty intentions are related with use of an internet portal. Similarly, the present study contributes to the literature that examines role of loyalty intention for recovery.

This study helps practitioners in examining the aspects of consumer behavior of taxi aggregator service users. Furthermore, considering the oligopolistic nature of Indian taxi aggregator service market, results of this study would help marketers in designing marketing strategies. These marketing strategies would emphasize on important e-service quality attributes like efficiency privacy and contact for staying competitive. The models proposed in this study answer the question how contact, privacy, and efficiency affect the perceived value and brand loyalty intention. The outcomes of the study indicate that the perceived value may be achieved by managing the contact, privacy, and efficiency aspects effectively. The model that considered brand loyalty intention as a dependent variable answers the question, how understanding impacts of efficiency, privacy, and contact would improve brand loyalty intention of taxi aggregator services? The outcomes of present study would help practitioners in mapping the issues related with efficiency, privacy, and contact in the context of taxi aggregator services for improving brand loyalty intention. The mangers may use these models to reflect on advantages of managing perceived value in short term and brand loyalty intention for long term. Koller et al. (2011) reported that in a long run, higher levels of brand loyalty are achieved by fulfilling perceived values defined by the customer in a short run.

Deshmukh \& Haleem (2020) viewed pandemic as a opportunities to develop capabilities by preparing context specific models. The outcomes of present study have introduced models suitable for taxi-aggregator service context. These models would help in formulating customer retention strategies for the post-COVID recovery. Kulkarni et al. (2016) reported that managing context and process helps in formulating a competitive strategy. The results of the study provide insights to the mobile application designers who 
could improve the technological efficiency of application for making it easy to use. This would further improve the context and process fit. As per the results, this would increase the both perceived value and the brand loyalty intention leading to enhanced customer retention. The results of the study indicate that the role of e-service constructs stays relevant for the taxi aggregator services.

\section{Limitation and Future Scope}

The present study has few limitations. The outcomes of the study are confined to the Indian taxi aggregator service users. The study used cross-sectional data for analysis; therefore, causality may not be confirmed. The focus on taxiaggregator service users could be another limitation of this study. In future, applicability of the proposed model may be checked for mobile application users of delivery applications (like Swiggy and Zomato), entertainment applications (like Hotstar and Zee5), and payment applications (like GooglePay and Paytm). This study has not investigated the mediating role of perceived value and moderating role of other variable (like service used). Possible mediator (customer satisfaction, Carlson \& O'Cass, 2011) and moderators may be identified, and role of such variables on the various relationships may be examined. Insights gained through future studies will help in enhancing the predictability and generalizability of the models proposed and validated in this study. Another limitation could be the lesser emphasis on the real-life scenarios as these applications are used in dayto-day activities. To enhance the theoretical and practical relevance of the study, the researchers are planning to conduct focus group discussions with practitioners as a future scope of the study.

\section{Key Questions Reflecting Applicability in Real Life}

1. Which factors are to be considered while designing a mobile-based service delivery application?

2. How to facilitate technology-based interactions and contact with customer for a better post-pandemic taxiaggregator service?

3. How to address privacy concerns of customers for ensuring data privacy to enhance trust?

4. How improving the technological efficiency would help in enhancing customer loyalty for mobile application usage?

5. What are the dimensions that facilitate the efficiency of mobile applications?

6. What is the role and relevance of brand loyalty intention for food delivery and payment applications?

\section{Appendix}

\section{Contents of Questionnaire}

See Appendix Tables 7, 8, 9, 10.

Table 7 Questions about demographic information

\begin{tabular}{llll}
\hline No. & Question & Options & \\
\hline 1 & Do you use online apps? & Yes & No \\
2 & Gender & Male & Female \\
3 & Profession & Self-employed & Salaried-employed \\
4 & $\begin{array}{c}\text { Do you use taxi aggrega- } \\
\text { tor apps? (e.g., Ola) }\end{array}$ & Yes & No \\
\hline
\end{tabular}

Table 8 Sub-items of constructs related to E-Service Quality

\begin{tabular}{ll}
\hline Construct & Item \\
\hline Efficiency & The Mobile Application (app) loads quickly \\
& The Mobile Application (app) is simple to use \\
& The Mobile Application (app) is easy to launch \\
Privacy & The Mobile Application (app) protects information about shopping behaviour \\
& The Mobile Application (app) does not share personal information with other sites \\
The Mobile Application (app) protects information related to my credit/debit card
\end{tabular}

Table 9 Sub-items of construct perceived value 
Table 10 Sub-items of construct Brand Loyalty Intention

Brand Loyalty Intentions

I shall say positive things about the service provider to other people

I shall recommend the service provider to someone

I shall encourage friends and others to avail service offered by the service provider

I shall consider this service provider as my first choice for future transactions

I am planning to avail services from this provider in the coming months/weeks
Acknowledgements We thank the anonymous reviewers for helping us in improving the manuscript. Their neutral, critical, and constructive observations helped us in continuously adding value to the manuscript. These suggestions made this manuscript practice oriented. The authors are thankful to the guest editors and editorial team for extending their timely support and cooperation. We also convey our thanks to Vijay Patil School of Management (VPSM), Navi Mumbai and National Institute of Industrial Engineering (NITIE), Mumbai for providing the infrastructural resources and encouragement throughout the process.

Author Contributions This study is a result of original contributions of the authors. The Conceptualization, Questionnaire Designing, Data collection, Analysis, and Manuscript writing were done by corresponding author. The Methodology of the study was designed by the co-author.

Funding The authors have no relevant research grant and research support information to disclose. There were no funding agencies involved that provided research grant and research support. There is no organization/s that may gain or lose financially through publication of this manuscript.

\section{Declarations}

Conflict of Interest Financial: The authors have no financial or proprietary interests in any material discussed in this article. Non-Financial: The authors have no conflicts of interest to declare that are relevant to the content of this article. All authors certify that they have no affiliations with or involvement in any organization or entity with any financial interest or non-financial interest in the subject matter or materials discussed in this manuscript.

Employment The authors have no recent, present, or anticipated employment by any organization that may gain or lose financially through publication of this manuscript.

Data Transparency All authors ensure that all data (288 anonymous responses) as well as software application and code (R-Software; PLSPM) support the published claims and comply with field standards.

\section{References}

Aladwani, A. M., \& Palvia, P. C. (2002). Developing and validating an instrument for measuring user-perceived web quality. Information and Management, 39, 467-476. https://doi.org/10.1016/S03787206(01)00113-6

Anderson, R. E., \& Srinivasan, S. S. (2003). E-satisfaction and e-loyalty: A contingency framework. Psychology and Marketing, 20(2), 123-138. https://doi.org/10.1002/mar.10063

Atinuke, A. A., Adewoye, J., \& Eweoya, I. O. (2016). E-Banking users' behaviour: E-service quality, attitude, and customer satisfaction.
International Journal of Bank Marketing, 34(3), 347-367. https:// doi.org/10.1108/IJBM-12-2014-0175

Barrutia, J. M., \& Gilsanz, A. (2009). E-Service quality: Overview and research agenda. International Journal of Quality and Service Sciences, 1(1), 29-50. https://doi.org/10.1108/17566690910945859

Bhattacharya, D., Gulla, U., \& Gupta, M. P. (2012). E-service quality model for Indian government portals: Citizens' perspective. Journal of Enterprise Information Management, 25(3), 246271. https://doi.org/10.1108/17410391211224408

Blut, M. (2016). E-service quality: Development of a hierarchical model. Journal of Retailing, 92(4), 500-517. https://doi.org/ 10.1016/j.jretai.2016.09.002

Carlson, J., \& O'Cass, A. (2011). Developing a framework for understanding e-service quality, its antecedents, consequences, and mediators. Managing Service Quality, 21(3), 264-286. https:// doi.org/10.1108/09604521111127965

Chang, H. H., Wang, Y. H., \& Yang, W. Y. (2009). The impact of e-service quality customer satisfaction and loyalty on e-marketing: Moderating effect of perceived value. Total Quality Management \& Business Excellence, 20(4), 423-443. https://doi. org/10.1080/14783360902781923

Chiou, J., \& Shen, C. (2006). The effects of satisfaction, opportunism, and asset specificity on consumers' loyalty intention toward internet portal sites. International Journal of Service Industry Management, 17(1), 7-22. https://doi.org/10.1108/0956423061 0651552

Cox, J., \& Dale, B. G. (2001). Service quality and e-commerce: An exploratory analysis. Managing Service Quality, 11(2), 121131. https://doi.org/10.1108/09604520110387257

Cristobal, E., Flavian, C., \& Guinalíu, M. (2007). Perceived e-service quality (PeSQ) measurement validation and effects on consumer satisfaction and web site loyalty. Managing Service Quality, 17(3), 317-340. https://doi.org/10.1108/09604520710744326

Dabholkar, P. A., \& Overby, J. W. (2005). Linking process and outcome to service quality and customer satisfaction evaluationsAn investigation of real estate agent service. International Journal of Service Industry Management, 16(1), 10-27. https://doi.org/10. 1108/09564230510587131

Dash, N., Wappelhorst, S., \& Bandivadekar, A./International Council on Clean Transportation. (2021). Updated Analysis of Incentives for electrifying India's four-wheeler ride-hailing fleet. Working Paper 2021-18.

Deshmukh, S. G., \& Haleem, A. (2020). Framework for manufacturing in post-Covid-19 world order: An Indian perspective. International Journal of Global Business and Competitiveness, 15, 49-60. https://doi.org/10.1007/s42943-020-00009-1

Dhir, S., \& Dhir, S. (2018). Organizational capability and performance improvement: A study of e-commerce firms in Indian context. International Journal of Global Business and Competitiveness, 13(1), 35-51.

Einasto, O. (2014). Investigating e-service quality criteria for university library: A focus group study. New Library World, 115(1), 4-14. https://doi.org/10.1016/j.sbspro.2014.07.163 
Elsharnouby, T.H., \& Mahrous, A. A. (2015) Customer participation in online co-creation experience: the role of e-service quality. Journal of Research in Interactive Marketing, 9(4), 313-336. https:// doi.org/10.1108/JRIM-06-2014-0038

Gera, R. (2011). Modelling the service antecedents of favourable and unfavourable behaviour intentions in life insurance services in India An SEM study. International Journal of Quality and Service Sciences, 3(2), 225-242. https://doi.org/10.1108/1756669111 1146113

Grewal, D., Krishnan, R., Baker, J., \& Borin, N. (1998). The effect of store name, brand name and price discounts on consumers' evaluations and purchase intentions. Journal of Retailing, 74(3), 331-352. https://doi.org/10.1016/S0022-4359(99)80099-2

Hair, J. F., Sarstedt, M., Hopkins, L., \& Kuppelwieser, V. G. (2014). Partial least squares structural equation modeling (PLS-SEM) An emerging tool in business research. European Business Review, 26(2), 106-121. https://doi.org/10.1108/EBR-10-2013-0128

Hair, J. F., Sarstedt, M., Risher, J. J., \& Ringle, C. M. (2019). When to use and how to report the results of PLS-SEM. European Business Review, 31(1), 2-24. https://doi.org/10.1108/EBR-11-2018-0203

Heim, G. R., \& Field, J. M. (2007). Process drivers of e-service quality: Analysis of data from an online rating site. Journal of Operations Management, 25, 962-984. https://doi.org/10.1016/j.jom.2006. 10.002

Herington, C., \& Weaven, S. (2009). E-retailing by banks: e-service quality and its importance to customer satisfaction. European Journal of Marketing, 43(9), 1220-1231. https://doi.org/10.1108/ 03090560910976456

Huang, A., \& Jahromi, M. F. (2021). Resilience building in service firms during and post COVID-19. The Service Industries Journal, 41(1-2), 138-167. https://doi.org/10.1080/02642069.2020. 1862092

Internet and Mobile Association of India. (2017). Mobile Internet Report. Agency-KANTAR IMRB.

Jabnoun, N., \& Hassan Al-Tamimi, H. A. (2003) Measuring perceived service quality at UAE commercial banks. International Journal of Quality \& Reliability Management, 20(4), 458-472. https://doi. org/10.1108/02656710310468614

Jain, N. K., Kamboj, S., Kumar, V., \& Rahman, Z. (2017). Examining consumer-brand relationships on social media platforms. Marketing Intelligence \& Planning, 36(1), 63-78. https://doi.org/10. 1108/MIP-05-2017-0088

Jain, V. K., Gupta, A., \& Verma, H. (2020). Millennials green consumption behavior and its linkage to firms marketing competitiveness: Findings from select study in Uttarakhand. International Journal of Global Business and Competitiveness, 15, 94-105. https://doi.org/10.1007/s42943-020-00017-1

Jayawardhena, C. (2004). Measurement of service quality In internet banking: The development of an instrument. Journal of Marketing Management, 20, 185-207. https://doi.org/10.1362/0267257047 73041177

Kalia, P. (2017). Service quality scales in online retail: Methodological issues. International Journal of Operations \& Production Management, 37(5), 630-663. https://doi.org/10.1108/ IJOPM-03-2015-0133

Kandulapati, S., \& Bellamkonda, R. S. (2014). E-service quality: A study of online shoppers in India. American Journal of Business, 29(2), 178-188. https://doi.org/10.1108/AJB-05-2013-0030

Katono, I. W. (2011). Student evaluation of e-service quality criteria in Uganda: The case of automatic teller machines. International Journal of Emerging Markets, 6(3), 200-216. https://doi.org/10. 1108/17468801111144049

Kaufmann, L., \& Gaeckler, J. (2015). A structured review of partial least squares in supply chain management research. Journal of
Purchasing and Supply Chain Management, 21(4), 259-272. https://doi.org/10.1016/j.pursup.2015.04.005

Keeney, R. L. (1999). the value of internet commerce to the customer. Management Science, 45(4), 533-542. https://www.jstor.org/stable/2634822

Kim, H., \& Niehm, L. S. (2009). The impact of website quality on information quality, value, and loyalty intentions in apparel retailing. Journal of Interactive Marketing, 23(3), 221-233. https://doi. org/10.1016/j.intmar.2009.04.009

Kim, J., \& Kim, C. (2010). E-service quality perceptions: A crosscultural comparison of American and Korean consumers. Journal of Research in Interactive Marketing, 4(3), 257-275. https://doi. org/10.1108/17505931011070604

Koller, M., Floh, A., \& Zauner, A. (2011). Further insights into perceived value and consumer loyalty: A "Green" perspective. Psychology \& Marketing, 28(12), 1154-1176. https://doi.org/10. 1002/mar.20432

Kulkarni, A., Ghuman, P., Gupta, S., \& Ujjwal Kumar. (2019). An Evidence-Based Analysis of Relevant Market: The Case of Ridesharing in Delhi-National Capital Region (India). Consumer Utility and Trust Society International-New Delhi.

Kulkarni, S., Verma, P., \& Mukundan, R. (2016). Extending canvas of manufacturing strategy: 8Ps model. International Journal of Global Business and Competitiveness, 11(1), 7-21.

Kundu, S., \& Datta, S. K. (2015). Impact of trust on the relationship of e-service quality and customer satisfaction. EuroMed Journal of Business, 10(1), 21-46. https://doi.org/10.1108/ EMJB-10-2013-0053

Kurt, S. D., \& Atrek, B. (2012). The classification and importance of E-S-Qual quality attributes: An evaluation of online shoppers. Managing Service Quality, 22(6), 622-637. https://doi.org/10. 1108/09604521211287589

Ladhari, R. (2010). Developing e-service quality scales: A literature review. Journal of Retailing and Consumer Services, 17, 464-477. https://doi.org/10.1016/j.jretconser.2010.06.003

Lee, G. G., \& Lin, H. F. (2005). Customer perceptions of e-service quality in online shopping. International Journal of Retail \& Distribution Management, 33(2), 161-176. https://doi.org/10.1108/ 09590550510581485

Loonam, M., \& O’Loughlin, D. (2008). Exploring e-service quality. Marketing Intelligence \& Planning, 26(7), 759-780. https://doi. org/10.1108/02634500810916708

Momaya, K. S. (2019). The past and the future of competitiveness research: A review in an emerging context of innovation and EMNEs. International Journal of Global Business and Competitiveness, 14(1), 1-10. https://doi.org/10.1007/ s42943-019-00002-3

Muylle, S., Moenaert, R., \& Despontin, M. (2004). The conceptualization and empirical validation of web site user satisfaction. Information \& Management, 41(5), 543-560. https://doi.org/10.1016/ S0378-7206(03)00089-2

Nguyen-Phuoc, D. Q., Vo, N. S., Diep Ngoc, Su., Nguyen, V. H., \& Oviedo-Trespalacios, O. (2021). What makes passengers continue using and talking positively about ride-hailing services? The role of the booking app and post-booking service quality. Transportation Research Part a: Policy and Practice, 150, 367-384. https:// doi.org/10.1016/j.tra.2021.06.013

Nitzl, C. (2016). The use of partial least squares structural equation modelling (PLS-SEM) in management accounting research: Directions for future theory development. Journal of Accounting Literature, 37(C), 19-35. https://doi.org/10.1016/j.acclit.2016. 09.003

O'Cass, A., \& Ngo, L. V. (2007). Market orientation versus innovative culture: Two routes to superior brand performance. European 
Journal of Marketing, 41(7/8), 868-887. https://doi.org/10.1108/ 03090560710752438

Oliver, R. L. (1999). Whence consumer loyalty? Journal of Marketing, 63(6), 33-44. https://doi.org/10.1177/00222429990634s105

Parasuraman, A. (2006). Modeling opportunities in service recovery and customer-managed interactions. Marketing Science, 25(6), 590-593. https://www.jstor.org/stable/40057195 .

Parasuraman, A., \& Grewal, D. (2000). The impact of technology on the quality-value-loyalty chain: A research agenda. Journal of the Academy of Marketing Science., 28(1), 168-174. https://doi.org/ 10.1177/0092070300281015

Parasuraman, A., Zeithmal, V. A., \& Malhotra, A. (2000). E-S-QUAL: A multiple-item scale for assessing electronic service quality. Journal of Service Research., 7(3), 213-233. https://doi.org/10. 1177/1094670504271156

Pearson, A., Tadisina, S., \& Griffin, C. (2012). The role of E-service quality and information quality in creating perceived value: Antecedents to web site loyalty. Information Systems Management, 29(3), 201-215. https://doi.org/10.1080/10580530.2012.687311

Rolland, S., \& Freeman, I. (2010). A new measure of e-service quality in France. International Journal of Retail and Distribution Management, 38(7), 497-517. https://doi.org/10.1108/0959055101 1052106

Sabiote, C. M., Frias, D. M., \& Castaneda, A. (2012). E-service quality as antecedent to e-satisfaction: The moderating effect of culture. Online Information Review, 36(2), 157-174. https://doi.org/10. 1108/14684521211229011

Sahadev, S., \& Purani, K. (2008). Modelling the consequences of e-service quality. Marketing Intelligence \& Planning, 26(6), 605-620. https://doi.org/10.1108/02634500810902857

Santos, J. (2003). E-service quality: A model of virtual service quality dimensions. Managing Service Quality, 13(3), 233-246. https:// doi.org/10.1108/09604520310476490

Sarstedt, M., Ringle, C. M., Henseler, J., \& Hair, J. F. (2012). On the Emancipation of PLS-SEM: A Commentary on Rigdon. Long Range Planning, 47(3), 154-160. https://doi.org/10.1016/j.lrp. 2014.02.007

Shih, H. (2004). An empirical study on predicting user acceptance of e-shopping on the Web. Information \& Management, 41, 351368. https://doi.org/10.1016/S0378-7206(03)00079-X

Sheng, T. \& Liu, C. (2010) An empirical study on the effect of e-service quality on online customer satisfaction and loyalty. Nankai Business Review International, 1(3), 273-283. https://doi.org/10. 1108/20408741011069205

Sohn, C., \& Tadisina, S. K. (2008). Development of e-service quality measure for internet-based financial institutions. Total Quality Management, 19(9), 903-918. https://doi.org/10.1080/14783 360802224412

Stamenkov, G., \& Dika, Z. (2015). A sustainable e-service quality model. Journal of Service Theory and Practice, 25(4), 414-442. https://doi.org/10.1108/JSTP-09-2012-0103

Stiakakis, E., \& Georgiadis, C. K. (2009). E-service quality: Comparing the perceptions of providers and customers. Managing Service Quality, 19(4), 410-430. https://doi.org/10.1108/09604 520910971539
Suh, Y. I., Ahn, T., \& Pedersen, P. M. (2013). Examining the effects of team identification, e-service quality (e-SQ) and satisfaction on intention to revisit sports websites. International Journal of Sports Marketing \& Sponsorship, 14(4), 2-19. https://doi.org/10.1108/ IJSMS-14-04-2013-B002

Trocchia, P. J., \& Janda, S. (2003). How do consumers evaluate Internet retail service quality? Journal of Services Marketing, 17(3), 243-253. https://doi.org/10.1108/08876040310474800

Yen, C., \& Lu, H. (2008). Effects of e-service quality on loyalty intention: An empirical study in online auction. Managing Service Quality: An International Journal, 18(2), 127-146. https://doi. org/10.1108/09604520810859193

Zeithmal, V. A. (1988). Consumer perceptions of price, quality, and value: a means-end model and synthesis of evidence. Journal of Marketing, 52 (3), 2-22. https://www.jstor.org/stable/1251446

Zeithmal, V. A., Berry, L. L., Parasuraman, A. (1996). The behavioural consequences of service quality. Journal of Marketing, 60 (2), 31-40. https://www.jstor.org/stable/1251929

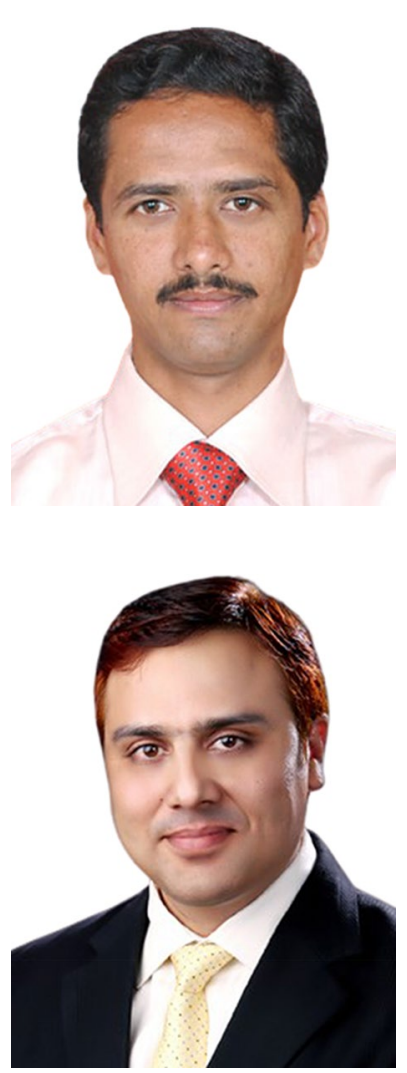

Avadhut Arun Patwardhan is an Assistant Professor in the area of Marketing at Vijay Patil School of Management (VPSM), Navi Mumbai in India. He pursued his Fellowship (Doctoral) programme from National Institute of Industrial Engineering (NITIE), Mumbai. He has published his 2 manuscripts in journals of international repute indexed in $\mathrm{ABDC}$ list.

Neeraj Pandey is an Associate Professor in the area of marketing at National Institute of Industrial Engineering (NITIE), Mumbai in India. He did his post-doc at Johns Hopkins University, USA in the area of pricing. He has authored two books and published in premier journals ranked 'A*' or 'A'. These journals are Australasian Marketing Journal, International Marketing Review, Journal of Business Research, Journal of Business and Industrial Marketing, Journal of Consumer Marketing, and Journal of Strategic Marketing, among others. His research interests are businessto-business marketing, and pricing strategy. 